\title{
Information needs of users of E'skia Mphahlele public library in the City of Tshwane municipality, South Africa
}

\author{
Mamotshabo Johanna Boloka ${ }^{1}$, Glenrose Velile Jiyane ${ }^{2}$ and Samuel Maredi Mojapelo ${ }^{3}$ \\ chabo.boloka@gmail.com ORCID: 0000-0001-8150-4849 \\ jiyaneg@unizulu.ac.za ORCID: 0000-0002-2856-3695 \\ mojapsm@unisa.ac.za ORCID: 0000-0002-6374-9153
}

\begin{abstract}
Received: 24 February 2019
Accepted: 14 May 2021

Provision of resources, such as libraries, to communities continues to be a priority for development and public libraries continue with their efforts to serve their users' diverse information needs. This paper describes the information needs of the E'skia Mphahlele library users and how the library meets their needs. The study sought to determine the information services offered by the E'skia Mphahlele library and the relevance of them to the needs of users. It found that barriers to users benefiting from the services include noise, poor internet connection and unavailability of up-to-date information resources, among others. The paper concludes that the information needs of E'skia Mphahlele public library users are not adequately met and, subsequently, their use of and access to information services is limited. The study recommends regular information needs surveys, the introduction of outreach information services to the community, an increased budget allocation for materials, and library staff training for improved service provision.
\end{abstract}

Keywords: Information needs, library users, E'skia Mphahlele Public library, South Africa, City of Tshwane municipality, library staff, public library services.

\section{Introduction}

One of the major roles of public libraries is to provide information services in a manner that is user-friendly and easily accessible to the public in order to meet their information needs (South African Community Library and Information Service Bill 2010). This role can assist with community support because public libraries have the fundamental responsibility of catering for the diverse and ever-changing informational, educational, socio-economic and cultural needs of their communities (Moodley 2013). Tahir, Mahmood and Shafique (2008: 1) stated that the present era is called the information era and that information has become the most important element for development in society. Thus, information is important for survival and growth in a society; Yusuf (2012) regards it as vital for individual growth and survival. Yusuf (2012) further stated that the progress of modern societies, as well as individuals, depends a great deal upon the provision of the right kind of information, in the right form and at the right time. Information is needed for citizens to make the correct decisions and to reduce uncertainties in their lives (Yusuf 2012).

Community needs assessment is crucial to ensure that libraries purchase relevant information resources to meet the dynamic and ever-changing needs of community members. MacKellar (2016: 66) stated that "if librarians have not done a community needs assessment for an extended period of time, the community could have changed to the extent that the library's mission is no longer relevant to the community". MacKellar (2016: 66) further articulated that effective library services and programmes need to meet the real needs of the community and make a real difference in their day-to-day lives. People visit libraries for different reasons. In an informal survey among Massachusetts public librarians, Malachowsky (2014) asked about libraries as access points for information. While $10 \%$ of survey respondents stated that they felt that their libraries were used primarily for internet access with no need for a librarian, the majority of the eighty-eight respondents indicated that the public libraries in Massachusetts were serving as access to both the internet and librarian assistance in equal measures. Patrons who came into the library solely for computer access would only navigate to their favourite websites without much assistance from librarians unless they were experiencing technical difficulties. Many who asked for help were those who needed basic help with logging in, printing documents and opening email attachments. Some patrons were overwhelmed by the information called up by a website and requested assistance from the librarian.

1. Mamotshabo Johanna Boloka is Lecturer in the Department of Information Science, University of South Africa

2. Veli Jiyane is Professor in the Department of Information Studies, University of Zululand, South Africa

3. Samuel Mojapelo is Associate Professor in the Department of Information Science, University of South Africa 


\section{Contextual setting}

The E'skia Mphahlele public library is situated at the corner of Stanza Bopape and Sisulu Streets in Tshwane, Gauteng Province. It is one of fifty-seven public libraries in the City of Tshwane municipality. According to City of Tshwane (n.d.), the focus at the E'skia Mphahlele public library is on "the provision of information, supporting education, the development and maintenance of a reading culture as well as the presentation and facilitation of various developmental outreach programmes". City of Tshwane (n.d.) indicated that the vision statement of the E'skia Mphahlele public library is to provide an information service that contributes meaningfully to the improvement of the quality of life of the people of Tshwane. The library's mission is that "the public library and information service shall act as an agent for community development and education by providing services to all people in Tshwane in their needs for lifelong learning, cultural expression and recreation" (City of Tshwane n.d.). E'skia Mphahlele is an urban public library serving a diverse group of library users. The E'skia Mphahlele public library operates from Monday to Friday from $09 \mathrm{~h} 00$ to $17 \mathrm{~h} 00$, and on Saturdays from $08 \mathrm{~h} 00$ to 12h50. The library has ten staff members and 6,925 registered users.

\section{Problem statement}

Public libraries continue to struggle to meet the increasingly diverse needs of their users. Provision of services is hampered by limited resources, making it difficult to satisfy all users. Libraries exist to provide services to meet the information needs of their user groups, and, as observed by Moodley (2013: 5), become "largely irrelevant to users" when they do not meet these needs. Even though there are policies guiding the provision of information and services that meet the needs of users in public libraries, it is evident that some libraries still do not meet user needs. This failure prompted an interest in learning about the situation at E'skia Mphahlele public library. This study therefore set out to reveal the information needs of the users of this public library to improve the library's relevance to its users.

\section{Research objectives}

The objectives of the study were to:

- describe the information needs of the E'skia Mphahlele library users and how they are met;

- determine the information services offered by the E'skia Mphahlele library;

- assess the relevance of information services offered by the E'skia Mphahlele library in order to meet the information needs of users;

- establish the challenges faced by users in accessing and using information and services in the E'skia Mphahlele public library;

- make recommendations based on the findings on how information needs of users at the E'skia Mphahlele public library could be met.

\section{Literature review}

In South Africa, the Department of Sports, Arts and Culture is a national department of government "tasked with creating an environment conducive to growth, development and flowering of South Africa's art, culture and heritage landscape" (Mnkeni-Saurombe \& Zimu 2013: 40). All public libraries in South Africa fall under the Department of Sports, Arts and Culture. However, it has been noted that, even in post-apartheid South Africa, community libraries are faced with an avalanche of daunting challenges against their mandate to provide library resources for all (Mojapelo 2018). Besides enormous challenges with funding and staffing, Mojapelo (2018) indicated that community libraries, particularly in disadvantaged rural communities, are not getting sufficient support from local governments. This problem of public libraries not meeting the information needs of their users is not only encountered in South Africa, but in other countries as well. Dudley (2013: 151) indicated that:

Harare's public libraries in Zimbabwe, especially those operated by the city of Harare, are suffering from serious financial constraints. ... This has stifled information provision; money to buy new books is difficult to come by as they have thus far depended on free and donations from donor agencies such as Aid International (AI) and United States Information Services (USIS). Most of the outdated materials the libraries harbour have proved to be of very little use to the users.

Public library users include children, young adults, adults, and people with special needs (people with disabilities) (Goulding 2016, Gilton 2012, Koontz \& Gubbin 2010). Goulding (2016: 109) observed that "even though 15- to 19-yearolds may not borrow books, they use facilities to study and access resources that are not available in their school libraries". People with disabilities need special facilities, for example, public libraries that cater to wheelchair-bound people. Kennedy (1997) cited by Thani and Hashim (2011: 139) argued that "the concept of information needs is similar to the physiological 
need for food and water". An information need is a situation or task which depends on many factors and changes as a person moves from one stage of life to another. For example, an information need for a grade 12 student may not be an information need when that student studies at tertiary level.

The information services rendered in a public library must be relevant to the needs of the community it serves. In her study, Moodley (2013) indicated that libraries need to be informed about users' information behaviour to understand users' information needs and how to fulfil these needs. According to Grover, Greer and Agada (2010), "to provide vital services relevant for the users' needs, libraries and information professionals need to be in constant touch with the changing needs of clientele, the social forces along with the technologies that influence them". Knowing the information needs of users enables library staff to design services to address and prioritise those needs. Koontz and Gubbin (2010: 37) stated that:

public libraries are required to provide services based on an analysis of the library information needs of the local community. In planning the services, clear priorities must be established and a strategy developed for services provision in the medium and long term. Services should be developed for identified target groups and only provided if such groups exist in the local community.

Dent, Geoff and Kevane (2014) indicated that a number of community members have learnt to read and write, both in Luganda and in English in the Kitengesa public library in rural Uganda, due to efforts of the librarians. Koontz and Gubbin (2010) indicated that in collecting and providing information, the public library should cooperate with other agencies to make the best use of available resources. Goulding (2016: 14) indicated that the key driver of change in the delivery of services that enable public libraries to extend new services and functionality to users has been information and communication technology (ICT). The rapid growth in the volume of available information and the continuing technological advances, which have radically affected the way information is accessed have had a significant effect on public libraries and their services (Koontz \& Gubbin 2010: 5). The challenge now for public libraries is how they manage their ICT resources to ensure that they are effectively supporting people's learning activities, opening up opportunities to the socially excluded and enabling engagement with public services through e-government (Goulding 2016: 14).

The Department of Sports, Arts and Culture pledges "not only to indulge the nation (South Africa) in creative outputs, but to provide access to information in a manner that establishes ties that bind among all people of the land, between the citizens and the state" (Mnkeni-Saurombe \& Zimu, 2013: 41). In view of this statement, community libraries strive to collect and provide access to information. Although public libraries are built in communities for the members to have free access to information, there are still cases where people do not make use of the libraries. In their study, Mutshewa et al. (2010) stated that public libraries are established to be used by communities. Surprisingly, many people in communities where there are public libraries do not make use of them. Lack of time, the distance to the library and irrelevance of the library resources and services to the respondents seemed to be the main barriers to library use (Mutshewa et al. 2010).

\section{Research methodology}

This study took a positivist stance and employed both quantitative and qualitative approaches. The main target population was E'skia Mphahlele library users, however, it was important for the librarians to participate as service providers. Samples were drawn from a total number of 6,925 library users and ten library staff. The quantitative data were collected from 363 conveniently sampled library users following the sample-size table by Payne and Payne (2004: 203), while qualitative data were purposively collected from eight library staff. Questionnaires were used to collect primary data from the users and interviews collected primary data from the librarians. All the 363 questionnaires distributed to the library users were returned, giving a $100 \%$ response rate. As only eight librarians were interviewed, the qualitative response rate was $80 \%$. Quantitative data were analysed using descriptive statistics which generated tables, frequencies and percentages. The qualitative data were thematically analysed.

\section{Results and discussion}

Table 1 shows the response rate for this study. According to Johnson and Christensen (2008), a response rate of around $70 \%$ is generally acceptable. This recommendation assumes that respondents and non-respondents are fairly similar (Mertens 2014: 191).

\subsection{Determining the information needs of E'skia Mphahlele public library users}

In order to determine the information needs of users of E'skia Mphahlele public library, users were asked to indicate their reasons for visiting the library. Librarians were also asked to discuss what the users request from the library. 
Table 1 Response rate of the respondents

\begin{tabular}{lcccc}
\hline Targets & Total number & Target number & Actual number & Response rate in \% \\
\hline Library users & 6,925 & 363 & 363 & 100 \\
Library staff & 10 & 10 & 8 & 80 \\
Totals & $\mathbf{6 , 9 3 5}$ & $\mathbf{3 7 3}$ & $\mathbf{3 7 1}$ & $\mathbf{9 9}$ \\
\hline
\end{tabular}

\subsubsection{Library users' responses about their information needs}

Library users provided multiple responses about their reasons for visiting the library, as can be seen in Table 2. The majority $(321 ; 88 \%)$ of respondents visited the library to read and study with personal notes, followed by 215 respondents $(59 \%)$ who visited the library for internet access. A further ninety-three $(26 \%)$ used library-based materials within the library. Seventy-four respondents (20\%) borrowed library materials. Only twenty-nine (8\%) visited the library to search library databases. It was interesting to note that only nineteen $(5 \%)$ visited the library to meet with friends and fifteen $(4 \%)$ for printing and making copies. The findings indicate that most of the library users made proper use of the library because they study, borrow material and use library-based materials. They are in line with Goulding's (2016: 109) observation that young adults (15-19 years) use library facilities to study and to access resources not available in their school libraries. It is better that few visit the library to meet their friends, because these meetings can make the noise level in the library unmanageable.

Table 2 Reason for visiting the library $(\mathrm{N}=363)$

\begin{tabular}{lc}
\hline & Responses \\
\hline Read and study with personal notes & $321(88 \%)$ \\
Borrow library materials & $74(20 \%)$ \\
Use library-based materials within the library & $93(26 \%)$ \\
Meeting with friends & $19(5 \%)$ \\
Search library databases & $29(8 \%)$ \\
Print / photocopy services & $15(4 \%)$ \\
Access internet & $215(59 \%)$ \\
Other & 0 \\
\hline
\end{tabular}

\subsubsection{Librarians' responses about users' information needs}

In order to discover what the users' information needs are, library staff were asked an open-ended question about the kind of information users ask for when visiting the library. The following were their responses:

- Users mostly want to find out about autobiographies, tertiary information and children programmes.

- Users ask for books, photocopy services and the use of computers.

- Users look for school-related information, especially study guides and novels for older people.

- Users visit the library to request teenage collections, do research on different subjects and use the Wi-Fi. Some request school-related and community information (directions).

- Users ask for assignment assistance, especially the students and school children. They also request recreational books and Wi-Fi connection.

- Users ask for hard copies, internet access, reference materials, both fiction and non-fiction books, toddler books, children's books, teenagers' books and CDs.

The library offers a wide range of information services to its users, giving job seekers, entrepreneurs, students and learners access to information, the internet and photocopy facilities, in addition to serving the reading needs of the public.

\subsection{The E'skia Mphahlele public library services}

It was important for this study to determine the information services offered in the E'skia Mphahlele public library. The library staff provided the researcher with a pamphlet which shows all the services that the library offers. They are listed as follows:

- General information

- Assistance with school projects

- Reference facilities

- Community information 
- A variety of books (fiction, non-fiction, large print, audio books, books in foreign and indigenous languages and books for the newly literate)

- Magazines and newspapers

- Internet access, PC and Wi-Fi use

- $\quad$ Photocopying and faxing

- Story hours and holiday programmes

- Items reservation and interlibrary loans

Apart from the services listed above, the library staff also register users for library membership and renew expired membership for easy access to the library. They also print users' documents upon request.

\subsection{Challenges experienced by library users when using the library and the challenges experienced by library staff when providing an information service}

For this study to make recommendations on how to improve the library services in the E'skia Mphahlele public library, it was important to find out about the challenges experienced by both the library users when accessing the library and the library staff when providing the information service to users.

\subsubsection{Challenges experienced by E'skia Mphahlele public library users}

The respondents were requested to indicate the challenges they experience when they access the library. The question was open-ended, where each user had to state their challenges. The findings are presented below by theme:

Noise:

Nearly half of the respondents $(180 ; 49 \%)$ indicated that the level of noise in the library was unbearable to such an extent that some ended up losing focus on what they were doing. The respondents mentioned instances where they experienced a high level of noise:

- Most of the time when I read, other students make a noise with their friends and this makes me lose concentration in my studies.

- $\quad$ There is no noise control; discussions are held in a no-group study zone.

- People talk loudly in the reading rooms as if the library is a social centre.

A quarter of the respondents (eighty-nine; 25\%) mentioned that people using cellphones in areas designated for studying caused a lot of noise and disturbances, together with those chatting with friends. Although Wishart (2012:2) opined that libraries should be a noisy place for the community to gather and exchange information, most library users complained about the noise level in the library. Users believe that noise in the library distracts them from what they are supposed to be doing. Wishart (2012: 2) believes that the library is a centre for socialisation, conversation and communication, saying that "a library can be a central meeting place for people to connect, learn and share".

\section{Unprofessional staff}

Most of the users $(190 ; 52 \%)$ complained that some of the library staff members had a negative attitude towards them when they required help. The following are some representative responses about staff being unprofessional when rendering information service to users:

- $\quad$ There is one staff member who is rude; she needs to improve on her attitude towards people.

- The staff at reception are rude ... and are not helpful at all.

- $\quad$ Staff is sometimes unprofessional; they don't know how to treat library users.

These responses indicate that some of the library staff do not deal well with library users when they request information. Their behaviour might be because public library users request diverse information services that may be beyond what libraries can offer. Sometimes library staff may not be aware that they are unconsciously treating users "as helpless clients rather than as competent citizens or demanding consumers" (Johannsen 2015: 38).

Slow internet

A total of 159 respondents (44\%) complained about the speed of the internet. Because of the slow internet, most users spend too much time on computers which means that other users are unable to use the computers themselves, thereby rendering their library visits fruitless. 
The unavailability of study materials

A total of 205 respondents (56\%) complained about the unavailability of study materials they needed in the library. Because the library runs short of current materials due to the unavailability of funds, it is advisable that the library staff familiarise themselves with other libraries and request library items through interlibrary loans.

\section{Library opening hours}

One hundred and ninety-eight respondents (54\%) complained about the opening hours of the library. The number of respondents not satisfied with the library opening hours was more than half $(198 ; 54 \%)$. They indicated that the library's opening hours were not sufficient for them, especially when they need to prepare for examinations. They indicated that it would be better if the library could open at least at $08 \mathrm{~h} 00$ in the morning and close at $18 \mathrm{~h} 00$ in the evening. The library should therefore review its opening and closing hours in order to satisfy the library users' needs.

\section{Insufficient library space}

One hundred and sixty-six respondents $(46 \%)$ indicated that the library space was insufficient. Some indicated that they would have to sit and study on the library sofas because of limited space in the reading room, implying that users struggle to study comfortably because of the insufficient space in the library.

It is not only E'skia Mphahlele public library users who experience challenges in accessing library services to meet their information needs. Mamafha (2013: 105) conducted a study in the use of ICTs at Ekurhuleni municipal libraries in which users also complained about the staff attitude when seeking help, especially first-time users of ICTs who rely on staff for guidance. Members of staff in libraries need to be available all the time to provide expert guidance to users as they select the materials they seek to borrow from libraries (Zulu 2014: 133). Snead (2014: 467) said that public libraries often lack the necessary resources to develop government information services adequately and to train personnel to deliver the services, or they lack the financial support from government for development and delivery of services.

\subsubsection{Challenges experienced by librarians when providing information to users}

In order to improve library services so that the information needs of library users can be catered for, it was important for this study to determine challenges library staff experience when providing an information service to the E'skia Mphahlele library users. Respondents were asked to share the challenges that they experience when they provide information services to library users. The following were the challenges they listed:

- There are not enough books in stock so when users request books that are not in stock, they are usually referred to the National Library of South Africa because the National Library receives copies of all books published.

- Budget constraints result in out-dated materials.

- Users damage library books.

- Users steal books and library systems (3M Machine) are unreliable.

- The collection is out-dated, some library staff are not information literate (some cannot even request books on Sabinet), and there is a lack of basic resources such as a colour printer.

- Sometimes users are afraid to say what they actually want, for example, people looking for information on how to live a good life with HIV/AIDS. Library staff have to struggle to understand what the user is looking for. They conduct reference interviews but can encounter language barriers. Sometimes users are requested to write down their needs as they cannot be heard when speaking.

It has been discovered that not only E'skia Mphahlele public library staff experience challenges when providing an information service to library users. Zulu (2014: 141) mentioned that library facilities such as buildings, space within the library buildings, shelves and seating arrangement for users were found to be unsatisfactory in most public libraries in Zambia. Furthermore, electronic facilities such as computers, printers, internet, projectors, scanners, binding machines, photographic equipment, optical storage devices and photocopying machines are often lacking (Zulu, 2014: 141). Skarzynski and Nassimbeni (2016: 26) indicated that the impact of a public library is difficult to measure because of the diversity of its users and the many reasons for which they might use the library. Dudley (2013: 151) found that the other challenge for Harare public libraries is related to low staffing levels which make it difficult to manage day-to-day activities in the library. 


\subsection{Ways in which the library staff address the challenges}

The E'skia Mphahlele library staff were asked to indicate how they address the challenges they experience when providing information service to users. The following were the ways in which they address the challenges:

- They do interlibrary loans (ILL) when users request books that are not in stock.

- They conduct reference interviews when users are unable to state exactly what they are looking for.

- The Gauteng Provincial Library Service has subscribed the E'skia Mphahlele public library to OverDrive for e-books.

- They conduct in-house training for library staff.

- They refer users to other libraries (when they need materials not in stock) or internet cafés (when they need a colour printer).

- They keep backup systems for library management.

- They tighten security to avoid the loss of books and users' personal computers.

- They raise concerns during meetings with seniors.

- They keep statistics of books in high demand and purchase them when they have the budget.

- They recommend that users buy books at bookstores because of budget constraints in the library.

According to Zulu (2014: 135), ILL services involve cooperative activities between two or more libraries where seeking libraries can borrow, on behalf of their members, resources which are not in their collections from other libraries. The aim of the service is to satisfy the needs of the users and encourage them to use the library (Zulu 2014: 135).

\section{Conclusion and recommendations}

E'skia Mphahlele public library users visit the library for various reasons. The library is mostly used by students who bring their own study materials. However, this study has revealed that there is too much noise in the library, the internet is too slow, there are very limited current materials, space is limited, and library staff are not welcoming. This study also revealed that library books are regularly stolen. Therefore, the study recommends that the library should: train library staff in nontraditional library services, such as etiquette and customer care; review opening and closing hours; look for funding from non-governmental organisations to purchase relevant equipment for the library; monitor the noise level in the library; strengthen the internet connection; and ensure that the library's book detector (3M machine) is always functional. Finally, it recommends that the City of Tshwane municipality builds more libraries to accommodate all its community members.

\section{References}

City of Tshwane n.d. Community libraries. [Online]. http://www.tshwane.gov.za/sites/residents/Services/Pages/Community-Libraries.aspx (8 July 2021).

Dent V.F., Geoff, G. and Kevane, M. 2014. Rural community libraries in Africa: challenges and impacts. London: IGI Global.

Dudley, M.Q. 2013. Public libraries and resilient cities. Washington: American Library Association.

Gilton, D.L. 2012. Lifelong learning in public libraries: principle, programs, and people. Lanham, Md.: Scarecrow Press.

Goulding, A. 2016. Public libraries in the $21^{\text {st }}$ century: defining services and debating the future. Farnham: Ashgate.

Grover, R.J., Greer, E.R.C. and Agada, J. 2010. Assessing information needs: managing transformative library services. Santa Barbara: Libraries Unlimited.

Johannsen, C.G. 2015. Library user metaphors and services: how libraries look at their users. Berlin: Boston.

Johnson, B. and Christensen, L. 2008. Educational research: quantitative, qualitative and mixed approaches. London: SAGE.

Koontz, C. and Gubbin, B. 2010. IFLA public library guidelines: publication 147. $2^{\text {nd }}$ ed. London: Rowman \& Littlefield.

MacKellar, P.H. 2016. Meeting community needs: a practical guide for librarians. London: Rowman \& Littlefield.

Mamafha, T.M.M. 2013. Utilization of Information and Communication Technologies in public libraries at Ekurhuleni Metropolitan municipality, South Africa. MInf dissertation. Pretoria: University of South Africa.

Malachowsky, M. 2014. Public libraries participating in community health initiatives. Journal of Hospital Librarianship, 14(3): 295-302.

Mertens, D.M. 2014. Research and evaluation in education and psychology: integrating diversity with quantitative, qualitative and mixed methods. $4^{\text {th }}$ ed. London: SAGE.

Mnkeni-Saurombe, N. and Zimu, N. 2013. Towards tackling inequalities in South Africa: the role of community libraries. Information Development, 31(1): 40-52. DOI:10.1177/0266666913501681.

Mojapelo, S.M. 2018. Challenges faced by libraries in a democratic South Africa: a case of three community libraries in South Africa. Information Development, 34(4): 408-421. DOI:10.1177/0266666917712337.

Moodley, T.A. 2013. The information needs and information-seeking behaviour of community library users in Msunduzi branch libraries, Pietermaritzburg. MInf dissertation. Durban: University of Kwazulu-Natal.

Mutshewa, A., Grand, B., Totolo, A., Zulu, S., Sebina, P. and Jorosi B. 2010. Information behaviours of non-users of libraries in Botswana. African Journal of Libraries, Archives and Information Science, 20(1): 1-10. 
Payne, G. and Payne, J. 2004. Key concepts in social research. New Delhi: SAGE.

Phillip, G. 2001. The public library service: IFLA/UNESCO guidelines for development. Netherlands: International Federation of Library Association.

Skarzynski, J. and Nassimbeni, M. 2016. Evaluating the impact of the public library book collection: a case study of two public libraries in Cape Town. South African Journal of Libraries and Information Science, 82(1): 26-35.

Snead, J.T. 2014. Public libraries, evaluation and e-government. Library Quarterly: Information Community Policy, 84(4): 467-480.

South African Community Library and Information Service Bill. 2010. [Online]. http://www.dac.gov.za/sites/default/files/Legislations\%20Files/SA\%20Public\%20Library\%20\%20Info\%20Services\%2 OBill.pdf (26 September 2016).

Tahir, M., Mahmood, K. and Shafique, F. 2008. Information needs and information-seeking behaviour of arts and humanities teachers: a survey of the University of the Punjab Lahore, Pakistan. Library Philosophy and Practice. (ejournal), Paper 227. [Online]. http://digitalcommons.unl.edu/libphilprac/227.

Thani, R.A. and Hashim, L. 2011. Information needs and information seeking behaviours of social science graduate students in Malaysian Public Universities. International Journal of Business and Social Science, 2(4): 137-143.

Wishart, E. 2012. Libraries and information provision for African relief: reading and writing. Journal of the Reading Association of South Africa, 3(1): 2.

Yusuf, T.I. 2012. Information needs, sources and information seeking behaviour of women artisans in Offa Metropolis. Library Philosophy and Practice (e-journal), Paper 1201. [Online]. http://digitalcommons.unl.edu/libphilprac/1201.

Zulu, P. 2014. The importance of legislation in the provision of national and public library services in Zambia. MInf dissertation. Pretoria: University of South Africa. 